\title{
RISK FACTORS FOR MORTALITY IN PATIENTS WITH COVID-19: A SYSTEMATIC REVIEW
}

\author{
Ratna Yustinawati'), Anhari Achadi²) \\ 1)Master of Public Health Program, Faculty of Public Health, Universitas Indonesia \\ 2)Department of Health Administration and Policy, Faculty of Public Health, Universitas \\ Indonesia
}

\begin{abstract}
Background: SARS-CoV-2, a new strain of the coronavirus, caused a global outbreak of fatal acute pneumonia. Globally, WHO has recorded 709,511 deaths from COVID-19, and the number is increasing. This study aimed to determine the risk factors for mortality in COVID-19 patients.

Subjects and Method: A systematic review was conducted by searching for articles from ScienceDirect, PubMed, SpringerLink, Scopus, and Google Scholar databases. The inclusion criteria were open access, English-language, and full-text articles published in journals between 20019 and 2020. The keywords were (Coronavirus Disease 2019 AND clinical characteristics AND epidemiological characteristics AND comorbidities) OR (COVID-19 AND clinical characteristics AND epidemiological characteristics AND comorbidities). A total of eight articles was reviewed to answer the research question. The data were analyzed by PRISMA flow chart.

Results: Based on the reports from China and Korea, a total of 1,314 (100\%) COVID-19 patients who died was aged $\geq 60$ years with comorbidity, in which 845 (64\%) were male patients. Before the death of patients, the increase D-dimer level of $\geq 1 \mu \mathrm{g} / \mathrm{mL}$ and Sequential Organ Failure Assessment (SOFA) score of $\geq 4$ were reported. It indicated the occurrence of multi-organ failure and Acute Respiratory Distress Syndrome (ARDS). Most of the comorbidities were hypertension, diabetes mellitus, and cardiovascular diseases.

Conclusion: Risk factors for mortality in COVID-19 patients include age at $\geq 60$ years, male, and presence of comorbidity. The clinical features are D-dimer levels $\geq 1 \mu \mathrm{g} / \mathrm{mL}$, high SOFA score $(\geq 4)$, and ARDS. Comprehensive efforts are needed to identify risk factors early and conduct effective treatment timely to reduce the mortality of COVID-19 patients.
\end{abstract}

Keywords: SARS-CoV-2, COVID-19, risk factors, mortality, comorbidity

\section{Correspondence:}

Ratna Yustinawati. Master of Public Health Program, Faculty of Public Health, Universitas Indonesia, Depok, West Java, Indonesia. Email: ratnayustinawati@gmail.com. Mobile: +628179324304 .

The $7^{\text {th }}$ International Conference on Public Health Solo, Indonesia, November 18-19, 2020 | 71 https://doi.org/10.26911/the7thicph.01.26 